\title{
Distinct effects of different doses of kaempferol on D-GalN/LPS-induced ALF depend on the autophagy pathway
}

\author{
YUAN TIAN*, FENG REN* ${ }^{*}$ LING XU and XIANGYING ZHANG \\ Beijing Institute of Hepatology, Beijing Youan Hospital, Capital Medical University, Beijing 100069, P.R. China
}

Received February 24, 2021; Accepted June 24, 2021

DOI: $10.3892 / \mathrm{mmr} .2021 .12321$

\begin{abstract}
Kaempferol, a flavonoid compound, has various biological functions, such as anti-inflammatory and antitumor activities. Acute liver failure (ALF) is a lethal clinical syndrome that occurs due to severe damage of the liver function. In the present study, the mechanisms underlying the therapeutic effects of kaempferol in ALF were evaluated. An ALF mouse model was established using D-galactosamine (D-GalN; $700 \mathrm{mg} / \mathrm{kg}$ )/lipopolysaccharide (LPS; $10 \mu \mathrm{g} / \mathrm{kg}$ ). A total of $2 \mathrm{~h}$ before the administration of D-GalN/LPS, mice were pretreated with different doses of kaempferol $(2.5,5,10,20$ and $40 \mathrm{mg} / \mathrm{kg})$, and $6 \mathrm{~h}$ after injection of D-GalN/LPS, mice were euthanized. The survival rate, liver function and levels of inflammatory cytokines were assessed. The results demonstrated that kaempferol pretreatment protected hepatocytes from ALF induced by D-GalN/LPS via regulation of the autophagy pathway, both in vivo and in vitro. Pretreatment with a high dose of kaempferol significantly decreased the survival rates and increased severe liver damage; however, pretreatment with a low dose of kaempferol had the opposite effect. Furthermore, pretreatment with a high dose of kaempferol enhanced the levels of proinflammatory cytokines [TNF- $\alpha$, IL-6, IL-12p40, IL-1 $\beta$, C-X-C motif chemokine ligand (CXCL)-2, CXCL-10] and markers of the MAPK signaling pathway [phosphorylated (p)-JNK, p-ERK, p-p38], whereas pretreatment with a low dose of kaempferol had the opposite effect. Pretreatment with a high dose of kaempferol decreased autophagy, whereas pretreatment with a low dose of kaempferol increased autophagy in vivo and in vitro. It was also shown that pretreatment with 3-methyadenine or autophagy related 7 small interfering RNA, to inhibit autophagy, partially
\end{abstract}

Correspondence to: Dr Xiangying Zhang, Beijing Institute of Hepatology, Beijing Youan Hospital, Capital Medical University, 8 Xitoutiao Road, Youwai Street, Fengtai, Beijing 100069, P.R. China

E-mail: zhangxy2018@ccmu.edu.cn

${ }^{*}$ Contributed equally

Key words: kaempferol, acute liver failure, autophagy, liver inflammation, D-galactosamine/lipopolysaccharide abrogated the hepatoprotective effects of pretreatment with $5 \mathrm{mg} / \mathrm{kg}$ kaempferol in the ALF mouse model. These results demonstrate that the effects of different doses of kaempferol on D-GalN/LPS-induced ALF varies based on the dose, and that kaempferol exerted its effects via regulation of the autophagy pathway.

\section{Introduction}

Acute liver failure (ALF) is a fatal hepatic disease associated with rapid loss of liver function, resulting in multiorgan dysfunction, encephalopathy and coagulopathy in patients. This critical illness has fatal consequences, and the only treatment option is an emergency liver transplant (1). Therefore, an effective drug for treating ALF is urgently required.

Kaempferol is a flavonoid that is primarily extracted from the root of Kaempferia galanga L., and it is widely present in various natural plants, fruits, vegetables, beverages and teas $(2,3)$. Kaempferol possesses several pharmacological properties, including cardioprotective, neuroprotective, antioxidative, antidiabetic and anticarcinogenic effects (4). A growing number of studies have shown that kaempferol can reduce the risk of developing various cardiovascular diseases, diabetes and cancer, amongst other diseases (4-6). It has been reported that kaempferol may be associated with the treatment of numerous diseases. For example, in a time- and concentration-dependent manner, kaempferol can decrease HeLa cervical cancer cell viability and induce apoptosis by downregulating the activity of the PI3K/AKT signaling pathway (7). Previous research also revealed that kaempferol distinctly inhibited the proliferation of the EJ bladder cancer cell line by inducing S cell cycle arrest and apoptosis, and increasing the expression levels of phosphorylated (p)-p53 via regulation of the mitochondrial-mediated apoptotic signaling pathways (8).

The potential protective effects of kaempferol on liver injury have been previously demonstrated (9-11), where it has been shown to exhibit effective anti-inflammatory properties in liver cells (12). In addition, kaempferol has been demonstrated to significantly alleviate acute liver injury, inflammation and early hepatocyte apoptosis caused by propacetamol (13). Our previous study revealed that kaempferol pretreatment could alleviate liver damage in D-galactosamine (D-GalN)/lipopolysaccharide (LPS)-induced mice (14). However, the underlying molecular mechanisms via which kaempferol exerts it effects in ALF remain to be determined. 
Autophagy is an intracellular catabolic signaling pathway, which is a highly conserved evolutionarily process, where biomolecules and organelles can be degraded by the lysosomes. Autophagy is crucial for maintaining the homeostasis of cells and replenishing several types of substances for cell survival under stressful conditions (15). Autophagy is closely associated with liver disease. It has previously been observed that autophagy may suppress the growth of tumors in chronic liver disease, and impaired autophagy can lead to a significant increase in glycolysis in liver cancer cells (16). In addition, autophagy can protect against the accumulation of fat in hepatocytes during nonalcoholic fatty liver disease (17). In our previous study, it was identified that activation of autophagy protected mice from ALF by inhibiting GSK-3 $\beta$ activity (18). In current therapeutic research, the problem of drug toxicity remains a persistent issue. To the best of our knowledge, there are no previous studies showing the effects of different doses of kaempferol on ALF. Therefore, the toxicity of kaempferol requires further study.

Given the aforementioned information, in the present study, a mouse model of ALF induced by D-GalN/LPS was utilized, as it has been widely used to examine the underlying mechanisms of potential therapeutic drugs for the treatment of ALF $(19,20)$. The functional effects of different doses of kaempferol were determined, the survival rate, liver function and levels of inflammatory cytokines were assessed, and the related regulatory pathways were evaluated in the context of ALF.

\section{Materials and methods}

Animals and treatments. A total of 40 male wild-type mice (C57BL/6; age, 8-12 weeks) were purchased from Capital Medical University (CMU; Beijing, China). The mice were housed in a standard environment with a controlled temperature of $22 \pm 2^{\circ} \mathrm{C}$ and humidity of $55 \pm 5 \%$, under a 12 -h light/dark cycle. Animals were provided with ad libitum access to water and food. The animal experimental protocol was approved by the Institutional Animal Care and Use Committee of CMU (approval no. AEEI-2020-009 on 2019/12/30).

The mice were injected intraperitoneally with D-GalN (700 mg/kg; Sigma-Aldrich; Merck KGaA) and LPS (10 $\mu \mathrm{g} / \mathrm{kg}$; InvivoGen) to induce ALF, or were injected with an equivalent volume of normal saline. A total of $2 \mathrm{~h}$ before the administration of D-GalN/LPS, mice were pretreated with different doses $(2.5,5,10,20$ or $40 \mathrm{mg} / \mathrm{kg}$ ) of kaempferol (Sigma-Aldrich; Merck KGaA) via tail vein injection ( $n=8 /$ group). Survival analysis was conducted based on the number of survivors in each group. 3-methyladenine (3-MA; Sigma-Aldrich; Merck $\mathrm{KGaA}$ ) can be used to block autophagy, and chloroquine (CQ; Sigma-Aldrich; Merck KGaA) can be used to inhibit the fusion of lysosomes and autophagosomes, and are commonly used to assess autophagic flux $(21,22)$. 3-MA $(10 \mathrm{mg} / \mathrm{kg})$ or CQ $(60 \mathrm{mg} / \mathrm{kg})$ were administered intraperitoneally $2 \mathrm{~h}$ before the administration of D-GalN/LPS. The mice were anesthetized by intraperitoneal injection of pentobarbital sodium $(60 \mathrm{mg} / \mathrm{kg})$. Liver tissues were collected for further analysis. Blood samples $(\sim 100 \mu \mathrm{l})$ were collected from the eyeballs. Subsequently, mice were sacrificed by intraperitoneal injection of $100 \mathrm{mg} / \mathrm{kg}$ sodium pentobarbital after $24 \mathrm{~h}$, and death was confirmed by observing respiration and by using the corneal reflection method.

Serum aminotransferase activity. Blood samples were collected from the mice $6 \mathrm{~h}$ after D-GalN/LPS administration. Serum levels of alanine aminotransferase (ALT) and aspartate aminotransferase (AST), which are markers of hepatic damage, were measured using a multiparametric analyzer (AU 5400; Olympus Corporation) according to the manufacturer's protocol (23).

Histopathological analysis. Liver samples were fixed in $4 \%$ formaldehyde solution for $12 \mathrm{~h}$ at $4^{\circ} \mathrm{C}$ and embedded in paraffin wax, after which, they were sectioned $(4 \mu \mathrm{m})$ and stained using $\mathrm{H} \& \mathrm{E}$, according to routine procedure for histopathological evaluation; sections were stained with hematoxylin for $10 \mathrm{~min}$ and with eosin for $10 \mathrm{sec}$ at room temperature. Tissues were observed using a light microscope (magnification, x200).

Reverse transcription-quantitative $(R T-q) P C R$. Total RNA was isolated from liver tissues using TRIzol ${ }^{\circledR}$ reagent (Invitrogen; Thermo Fisher Scientific, Inc.) according to the manufacturer's protocol. RT of RNA $(2.5 \mu \mathrm{g})$ into cDNA was performed using a SuperScript III first-strand synthesis system according to the manufacturer's protocol (Invitrogen; Thermo Fisher Scientific, Inc.). A DNA Engine with a Chromo 4 detector (MJ Research, Inc.; Bio-Rad Laboratories, Inc.) was used for qPCR. The final reaction volume was $20 \mu \mathrm{l}$ and consisted of $1 \mathrm{X}$ super mix (Platinum SYBR-Green qPCR kit; Invitrogen; Thermo Fisher Scientific, Inc.), $2 \mu \mathrm{l}$ cDNA and $0.5 \mu 1$ each primer. The amplification conditions were as follows: Initial denaturation at $50^{\circ} \mathrm{C}(2 \mathrm{~min}), 95^{\circ} \mathrm{C}(5 \mathrm{~min})$, followed by 50 cycles of $95^{\circ} \mathrm{C}$ $(15 \mathrm{sec})$ and $60^{\circ} \mathrm{C}(30 \mathrm{sec})$. The mRNA expression levels were calculated using the $2^{-\Delta \Delta \mathrm{Cq}}$ method (24). The sequences of the PCR primers used are listed in Table I and were produced by Sangon Biotech, Co., Ltd.

Western blotting. Liver tissue samples or cells were lysed in RIPA lysis buffer (Beyotime Institute of Biotechnology) supplemented with phosphatase and protease inhibitors, and the concentration was estimated using a Bradford Protein Assay kit (Beyotime Institute of Biotechnology). A total of $20 \mu \mathrm{g}$ protein per sample was loaded onto a $12 \%$ SDS gel, resolved using SDS-PAGE at $80 \mathrm{~V}$ for $30 \mathrm{~min}$ and $120 \mathrm{~V}$ for $1 \mathrm{~h}$, and then transferred to a PVDF membrane using a Bio-Rad blotting transfer system (Bio-Rad Laboratories, Inc.). The membranes were blocked with $5 \%$ skimmed milk at room temperature for $1 \mathrm{~h}$, and incubated overnight at $4^{\circ} \mathrm{C}$ with the following primary antibodies: $\beta$-actin $(1: 1,000$; cat. no. 8457S; Cell Signaling Technology, Inc.), p-JNK (1:1,000; cat. no. 4668S; Cell Signaling Technology, Inc.), p-ERK (1:1,000; cat. no. 4348S; Cell Signaling Technology, Inc.), p-p38 (1:1,000; cat. no. 9215S; Cell Signaling Technology, Inc.), LC3B (1:1,000; cat. no. 3868S; Cell Signaling Technology, Inc.), autophagy related 7 (Atg7; 1:1,000; cat. no. 8558S; Cell Signaling Technology, Inc.) and p62 (1:1,000; cat. no. 23214S; Cell Signaling Technology,Inc.). After washing, the membranes with TBS-0.5\% Tween-20 (TBS-T) and the corresponding HRP-conjugated secondary antibody (1:2,000; cat. no. 7074S; Cell Signaling Technology, Inc.) in $10 \mathrm{ml}$ blocking buffer was 
Table I. Sequences of the primers used for reverse transcription-quantitative PCR.

\begin{tabular}{lll}
\hline Gene & \multicolumn{1}{c}{ Forward primers $\left(5^{\prime}-3^{\prime}\right)$} & \multicolumn{1}{c}{ Reverse primers $\left(5^{\prime}-3^{\prime}\right)$} \\
\hline TNF- $\alpha$ & GCCTCTTCTCATTCCTGCTTGT & TTGAGATCCATGCCGTTG \\
CXCL-10 & AAGTGCTGCCGTCATTTTCT & GTGGCAATGATCTCAACACG \\
CXCL-2 & AGTGAACTGCGCTGTCAATG & TTCAGGGTCAAGGCAAACTT \\
IL-6 & GCTACCAAACTGGATATAATCAGGA & CCAGGTAGCTATGGTACTCCAGAA \\
IL-1 $\beta$ & TTGACGGACCCCAAAAGAT & GATGATCTGAGTGTGAGGGTCTG \\
IL-12p40 & CAGCTTCTTCATCAGGGACAT & CTTGAGGGAGAAGTAGGAATGG \\
IL-10 & ACTGCACCCACTTCCCAGT & TGTCCAGCTGGTCCTTTGTT \\
LC3 & AGCAGCATCCAACCAAAATC 7 & CTGTGTCCGTTCACCAACAG \\
HPRT & ACCCAGAAGAAGCTGAACGA & CTCATTTGCTGCTTGTTCCA \\
\end{tabular}

CXCL-10, C-X-C motif chemokine ligand-10; CXCL-2, C-X-C motif chemokine ligand-2; Atg7, recombinant autophagy related protein 7; HPRT, hypoxanthine guanine phosphoribosyl transferase.

added and incubated for $1 \mathrm{~h}$ at room temperature. Next, the membranes were washed three times with TBS-T for $30 \mathrm{~min}$, and signals were visualized using an ECL kit (Thermo Fisher Scientific, Inc.). Restore Western Blot Stripping Buffer was used to re-probe new target proteins in a same membrane (Thermo Fisher Scientific, Inc.). The blot was placed in Restore Western Blot Stripping Buffer and incubated for 5-15 min at $37^{\circ} \mathrm{C}$. Then, the blot was removed from the Restore Western Blot Stripping Buffer and washed in PBS for 15-20 min. Next, as mentioned previously, the blot was incubated with new primary and secondary antibodies. Densitometry analysis was performed using ImageJ (version 1.49p; National Institutes of Health).

Atg7 small interfering (si)RNA treatment in vivo. siRNA ( $3 \mathrm{mg} / \mathrm{kg}$; Shanghai Genepharma Co., Ltd.) and an Entranster ${ }^{\mathrm{TM}}$ in vivo transfection reagent (Engreen Biosystem Co.) were used to knock down Atg7 expression via the administration of a hydrodynamic tail vein injection in mice. After transfection for $24 \mathrm{~h}$, subsequent experimentation was performed. The sequence of Atg7 siRNA was 5'-GCAUCAUCUUCGAAGUGAATT-3'. Scrambled siRNA ( $3 \mathrm{mg} / \mathrm{kg}$ ) was used as a control and the sequence was 5'-UUCUCCGAACGUGUCACGUTT-3'. These steps were performed in accordance with the manufacturer's protocol.

Isolation of primary mouse hepatocytes. Hanks' solution containing collagenase was used to perfuse mouse livers when the mice were 7 weeks old, and, as described previously, live hepatocytes were separated using Percoll isocratic centrifugation at $4^{\circ} \mathrm{C}$ for $10 \mathrm{~min}$ at $10,000 \mathrm{xg}(25)$. The number of mice used was 3 , and they were sacrificed by intraperitoneal injection of $100 \mathrm{mg} / \mathrm{kg}$ sodium pentobarbital after $24 \mathrm{~h}$; death was confirmed by observing respiration and by using the corneal reflection method.

Starvation-induced autophagy in vitro. The most robust method of inducing autophagy is starvation of cells (26). Primary hepatocytes were transfected with the GFP-LC3 plasmid (1 $\mu \mathrm{g} / \mathrm{ml}$; Shanghai Genepharma Co., Ltd.) for $12 \mathrm{~h}$ at $37^{\circ} \mathrm{C}$, and were treated with serum-free medium for $4 \mathrm{~h}$ at $37^{\circ} \mathrm{C}$. The percentage of cells was calculated based on the number of GFP-LC3 puncta in the different treatment groups. GFP-positive cells were regarded as cells that exhibited bright, punctate staining. Per condition, $\sim 50$ cells were counted, and the experiment was repeated at least three times. Cells were observed using a fluorescence microscope (magnification, $\mathrm{x} 200$ ).

Statistical analysis. The results from three independent experiments are presented as the mean \pm SD. Survival analysis was conducted using a Kaplan-Meier plot with the log-rank test, and the P-value was corrected a by Bonferroni's test. Statistical differences were determined using one-way ANOVA followed by Bonferroni's post hoc analysis in GraphPad Prism version 7 (GraphPad Software, Inc.). $\mathrm{P}<0.05$ was considered to indicate a statistically significant difference.

\section{Results}

Effects of kaempferol on D-GalN/LPS-induced ALF. First, the effects of different doses of kaempferol on ALF induced by D-GalN/LPS in mice were examined. Different doses of kaempferol $(2.5,5,10,20$ or $40 \mathrm{mg} / \mathrm{kg})$ were intraperitoneally administered. As shown in the survival analysis (Fig. 1A), the survival rate of the 5 and $10 \mathrm{mg} / \mathrm{kg} \mathrm{kaempferol}$ group was significantly increased compared with that in the D-GalN/LPS-treated group, and the $5 \mathrm{mg} / \mathrm{kg}$ kaempferol group showed the highest survival rate. This result suggested that $5 \mathrm{mg} / \mathrm{kg}$ kaempferol treatment effectively reduced D-GalN/LPS-induced liver injury.

Pretreatment with and $40 \mathrm{mg} / \mathrm{kg}$ kaempferol resulted in higher serum ALT (sALT) and serum AST (sAST) levels compared with the D-GalN/LPS induced group; whereas the $2.5,5$ and $10 \mathrm{mg} / \mathrm{kg}$-treated mice exhibited lower levels of sALT and sAST, particularly the $5 \mathrm{mg} / \mathrm{kg}$ kaempferol group (Fig. 1C). Consistent with the ALT and AST activities, the liver histopathology in the $20 \mathrm{mg} / \mathrm{kg}$ kaempferol group showed increased hepatocyte injury, similar to that of the D-GalN/LPS group, but mice in the groups treated with 


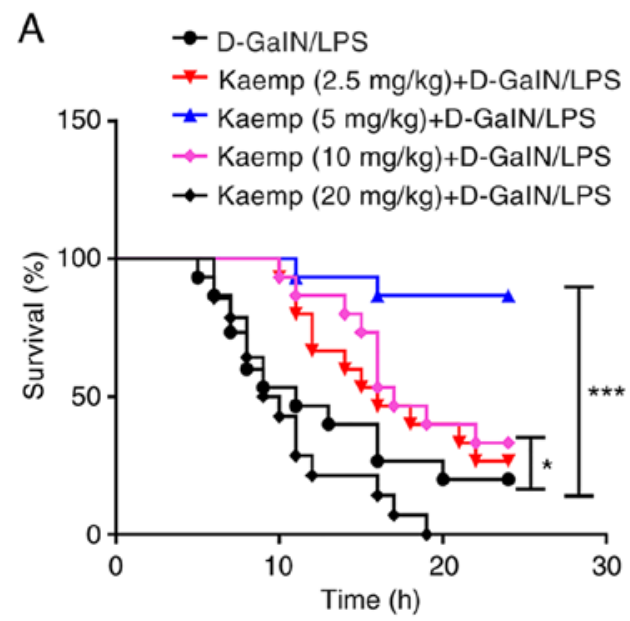

B
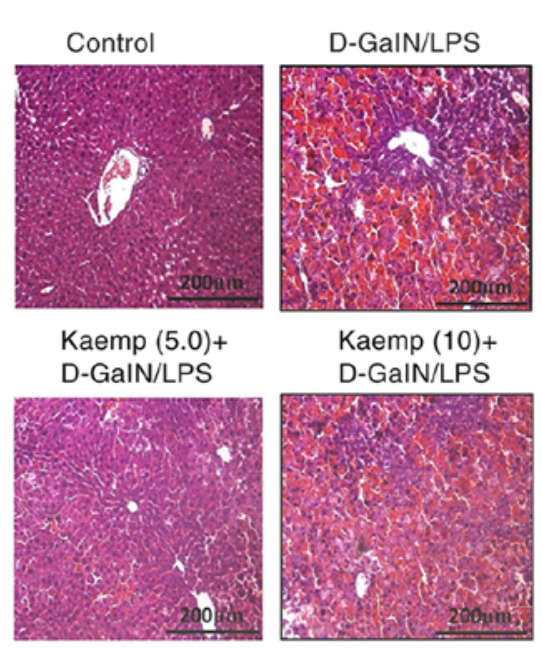

Kaemp (10)+ D-GaIN/LPS

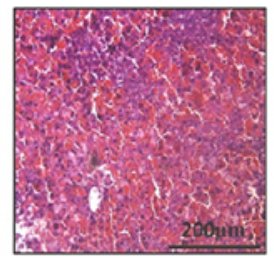

Kaemp (2.5)+

D-GalN/LPS

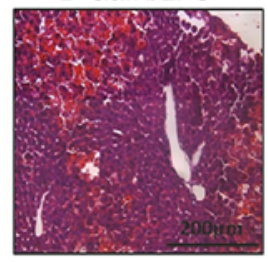

Kaemp (20)+

D-GaIN/LPS

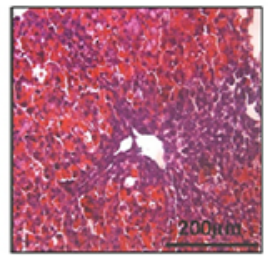

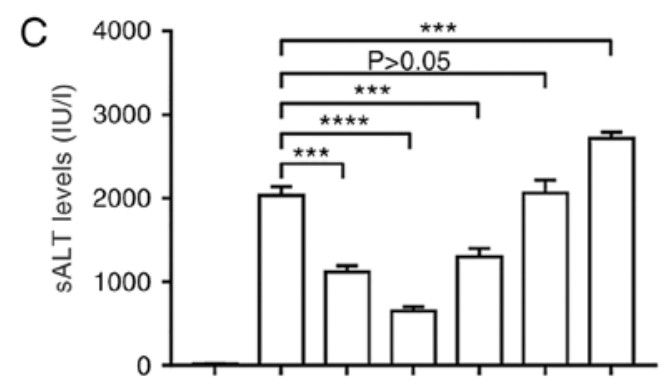
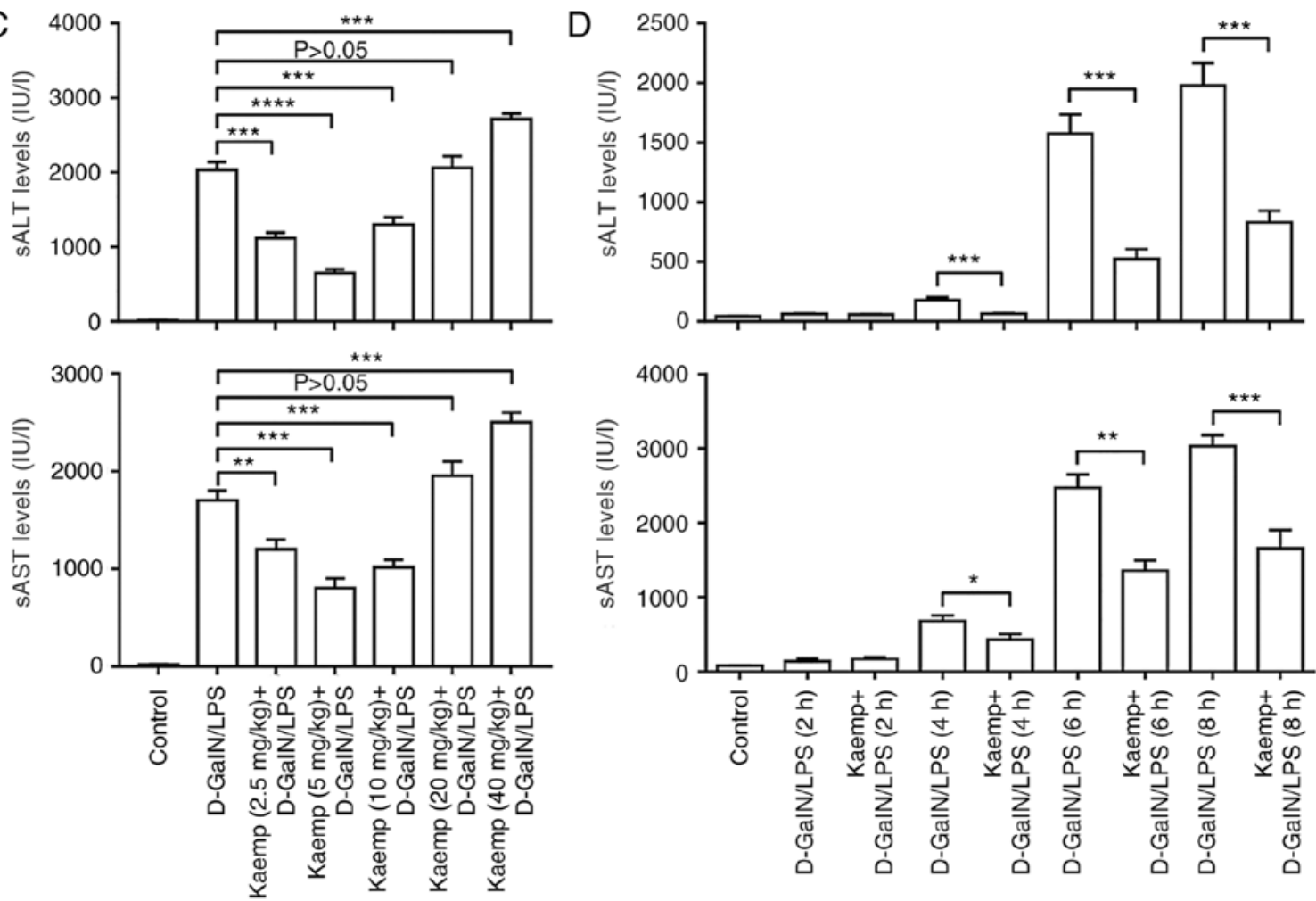

Figure 1. Effects of different doses of kaemp on D-GalN/LPS-induced ALF. Mice treated with kaemp + D-GalN/LPS were administered kaemp (2.5, 5, 10, 20 or $40 \mathrm{mg} / \mathrm{kg}$; intravenously) prior to or after D-GalN/LPS injection $(\mathrm{n}=20)$. Control mice were pretreated with saline before D-GalN/LPS injection $(\mathrm{n}=20)$. (A) Survival rates of ALF-induced mice treated with different doses of kaemp and the PBS + D-GalN/LPS-treated group. ${ }^{*} \mathrm{P}<0.05,{ }^{* * *} \mathrm{P}<0.001$ vs. D-GalN/LPS treated group. (B) H\&E-stained liver sections of ALF induced model mice treated with different doses of kaemp and the D-GalN/LPS-treated mice. Scale bar, $200 \mu \mathrm{m}$. (C) sAST and sALT enzyme levels in the different groups. (D) sAST and sALT enzyme levels in the different groups, including mice pretreated with $5 \mathrm{mg} / \mathrm{kg}$ kaemp, were measured to evaluate liver injury in mice after $2,4,6$ and $8 \mathrm{~h}$ of D-GalN/LPS administration. ${ }^{*} \mathrm{P}<0.05,{ }^{* * *} \mathrm{P}<0.01,{ }^{* * * *} \mathrm{P}<0.001,{ }^{* * * * *} \mathrm{P}<0.0001$. ALF, acute liver failure; sALT, serum alanine aminotransferase; sAST, serum aspartate aminotransferase; D-GalN/LPS, D-galactosamine/lipopolysaccharide; kaemp, kaempferol.

2.5 and $5 \mathrm{mg} / \mathrm{kg}$ kaempferol showed decreased hepatocyte injury, and the $5 \mathrm{mg} / \mathrm{kg}$ kaempferol group exhibited the lowest degree of injury (Fig. 1B).

Next, the protective effects of kaempferol $(5 \mathrm{mg} / \mathrm{kg})$ pretreatment on liver injury in mice 2, 4, 6 and $8 \mathrm{~h}$ after D-GalN/LPS administration was determined. The results demonstrated that the D-GalN/LPS-induced increases in sALT and sAST levels were significantly decreased by $5 \mathrm{mg} / \mathrm{kg}$ kaempferol after 4, 6 and $8 \mathrm{~h}$ (Fig. 1D). These results suggested that high doses of kaempferol can induce more severe injury, whereas pretreatment with low doses of kaempferol significantly increased the survival rates of mice and protected against ALF induced by D-GalN/LPS.

Effects of kaempferol on liver inflammation in mice with $D$-GalN/LPS-induced ALF. Our previous study revealed 

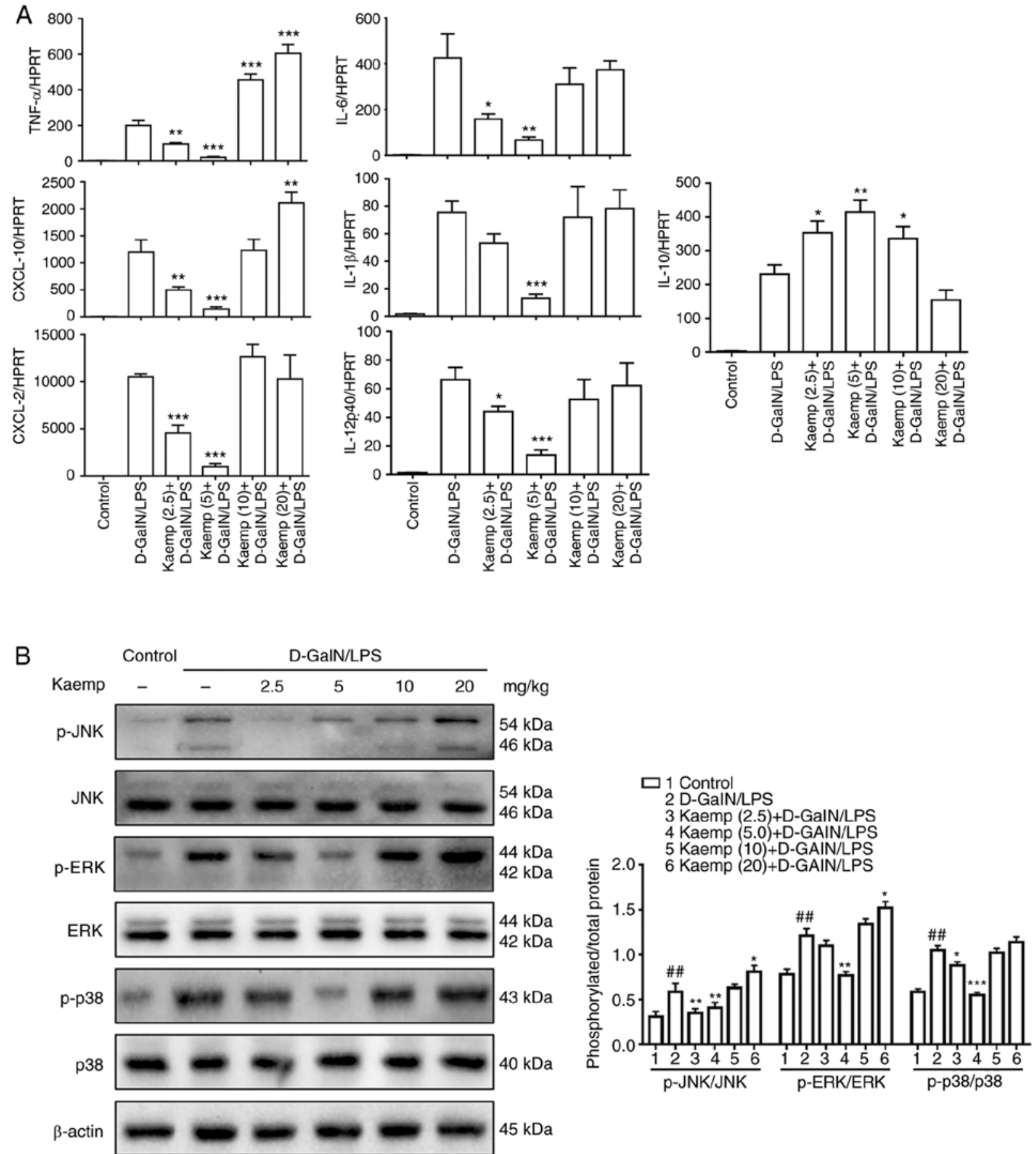

Figure 2. Effects of different doses of kaemp on liver inflammation in D-GalN/LPS-induced ALF. (A) Reverse transcription-quantitative PCR analysis was performed to determine the gene expression levels of cytokines and chemokines, including TNF- $\alpha$, IL-6, IL-12p40, IL-10, IL-1 $1 \beta$, CXCL-10 and CXCL-2, in the livers of mice in the different groups. (B) Western blot analysis to determine hepatic protein expression levels of p-JNK, JNK, p-ERK, ERK, p-p38, p38 and $\beta$-actin. Data are presented as the mean $\pm \mathrm{SD}$. ${ }^{\# \#} \mathrm{P}<0.01$ vs. control group; ${ }^{*} \mathrm{P}<0.05,{ }^{* *} \mathrm{P}<0.01,{ }^{* * *} \mathrm{P}<0.001$ vs. D-GalN/LPS group. D-GalN/LPS, D-galactosamine/lipopolysaccharide; kaemp, kaempferol; CXCL, C-X-C motif chemokine ligand; p-, phosphorylated.

that the inflammatory response served an important role in ALF (27). Therefore, whether liver inflammation was induced by the different doses of kaempferol in the D-GalN/LPS-induced ALF mice was next determined. As shown in Fig. 2A, compared with the D-GalN/LPS group, the mice pretreated with 2.5 and $5 \mathrm{mg} / \mathrm{kg}$ kaempferol exhibited lower gene expression levels of TNF- $\alpha$, IL-6, IL-1 $\beta$, IL-12p40, C-X-C motif chemokine ligand (CXCL)-10, CXCL-2 in the livers, and the $5 \mathrm{mg} / \mathrm{kg}$ kaempferol group exhibited the lowest levels. By contrast, pretreatment with 10 and $20 \mathrm{mg} / \mathrm{kg}$ kaempferol resulted in notably increased gene expression levels of these cytokines. Additionally, pretreatment with $2.5,5$ or $10 \mathrm{mg} / \mathrm{kg}$ kaempferol resulted in increased gene expression levels of IL-10 when compared with the D-GalN/LPS-induced mice, and the $5 \mathrm{mg} / \mathrm{kg}$ kaempferol group exhibited the highest levels.

Next, whether the MAPK signaling pathway was affected by different doses of kaempferol was assessed. The protein 
expression levels of p-JNK, JNK, p-ERK, ERK, p-p38, p38 were determined using western blotting. Mice treated with 2.5 or $5 \mathrm{mg} / \mathrm{kg}$ kaempferol exhibited reduced levels of these proteins, with the $5 \mathrm{mg} / \mathrm{kg}$ kaempferol group exhibiting the lowest levels. By contrast, pretreatment with 10 and $20 \mathrm{mg} / \mathrm{kg}$ kaempferol resulted in markedly increased expression levels of these proteins (Fig. 2B). Therefore, these results indicated that pretreatment with high doses of kaempferol can increase the hepatic inflammatory response, whereas pretreatment with a low dose of kaempferol can significantly decrease it in D-GalN/LPS-induced ALF.

Effects of kaempferol on liver autophagy in mice with $D$-GalN/LPS-induced ALF. Given that our previous study observed that autophagy serves a significant role in D-GalN/LPS-induced ALF (18), whether different doses of kaempferol affected liver autophagy in the D-GalN/LPS-induced ALF was next assessed. The results of the RT-qPCR analysis revealed that pretreatment with $2.5,5,10$ or $20 \mathrm{mg} / \mathrm{kg}$ kaempferol significantly increased the gene expression levels of LC 3 compared with the untreated D-GalN/LPS-induced ALF in mice (Fig. 3A). Moreover, pretreatment with $2.5,5$ and $20 \mathrm{mg} / \mathrm{kg}$ kaempferol increased the gene expression levels of Atg7, and the $5 \mathrm{mg} / \mathrm{kg}$ kaempferol group exhibited the highest expression levels of these genes. The western blot analysis produced consistent results. Pretreatment with $2.5,5,10$ or $20 \mathrm{mg} / \mathrm{kg}$ kaempferol resulted in increased LC3 protein expression, and the $5 \mathrm{mg} / \mathrm{kg}$ kaempferol group exhibited the highest expression levels. In addition, pretreatment with 2.5 and $5 \mathrm{mg} / \mathrm{kg}$ kaempferol significantly decreased the protein expression levels of p62, whereas 10 and $20 \mathrm{mg} / \mathrm{kg}$ kaempferol significantly increased its protein expression. Furthermore, pretreatment with 2.5, 5, 10 and $20 \mathrm{mg} / \mathrm{kg}$ kaempferol significantly increased the protein expression levels of Atg7, and the $5 \mathrm{mg} / \mathrm{kg}$ kaempferol group exhibited the highest expression levels (Fig. 3B).

To further demonstrate the effect of kaempferol $(5 \mathrm{mg} / \mathrm{kg}$ ) on autophagy flux, the fusion of lysosomes with autophagosomes was inhibited using CQ pretreatment. It was found that CQ pretreatment did not further increase LC3II conversion and did not further decrease p62 levels compared with the $5 \mathrm{mg} / \mathrm{kg}$ kaempferol pretreated D-GalN/LPS induced ALF mice (Fig. 3C). These data suggest that kaempferol pretreatment may facilitate autophagosome function and inhibit autophagic flux in D-GalN/LPS-induced ALF.

Effects of kaempferol on starvation-induced autophagy in vitro. To further support the results of the in vivo experiments, the effects of kaempferol on starved primary hepatocytes were assessed in vitro. To observe the formation of autophagosomes, the GFP-LC3 plasmid was transfected into hepatocytes. As shown in Fig. 4A, compared with that of the control group, the GFP-LC3 signal was weak in the starved group and high-dose kaempferol-treated groups, but was bright, with a lower number of puncta, in the low-dose kaempferol-treated groups.

Next, the protein expression levels of LC3, p62 and Atg7 were measured via western blotting (Fig. 4B). The starved and low-dose kaempferol-treated groups exhibited higher LC3 protein expression levels, and the high-dose kaempferol group exhibited lower expression levels compared with the control group. Furthermore, the low-dose kaempferol groups showed reduced protein expression levels of p62, and the high-dose groups also appeared to show decreased p62 expression compared with the control. Additionally, low-dose kaempferol groups showed reduced protein expression levels of Atg7, and the high-dose kaempferol groups exhibited lower expression levels compared with the control group. Collectively, the presence of autophagic flux was demonstrated by increased expression of LC3 and decreased expression of p62. Thus, the results suggest that pretreatment with low doses of kaempferol promotes the induction of autophagic flux, but that the pretreatment with high doses of kaempferol restrains the induction of autophagic flux in starvation-induced hepatocytes in vitro.

Kaempferol ameliorates injury in the livers of ALF model mice through autophagic mechanisms. The aforementioned experiments demonstrated that $5 \mathrm{mg} / \mathrm{kg}$ kaempferol significantly reduced ALF induced by D-GalN/LPS. To further determine whether pretreatment with $5 \mathrm{mg} / \mathrm{kg}$ kaempferol contributed to the induction of autophagy to protect against liver injury, Atg7 knockdown using siRNA was performed in vivo. The results indicated that 3-MA or Atg7 siRNA partially reversed kaempferol-mediated hepatoprotection in the ALF model mice, as shown by the increased levels of sALT and sAST (Fig. 5A), and the histological analysis showing a relatively less well-preserved liver architecture (Fig. 5B). Additionally, the protein expression levels of LC3, p62 and Atg7 were measured using western blotting (Fig. 5C). The Atg7 siRNA group had lower protein expression levels of LC3II and Atg7, and higher protein expression levels of p62. Furthermore, the expression levels of LC3II, Atg7 and p62 were assessed following pretreatment with 3-MA, and the expression levels of Atg7 were reduced with pretreatment of 3-MA. The results demonstrated that, compared with mice treated with kaempferol $(5 \mathrm{mg} / \mathrm{kg})$ and D-GalN/LPS, 3-MA pretreatment decreased conversion of LC3II and increased the degradation of p62 (Fig. 3C). These data indicated that pretreatment with $5 \mathrm{mg} / \mathrm{kg}$ kaempferol ameliorated liver injury by regulating autophagy in ALF model mice.

\section{Discussion}

Kaempferol is an ingredient in traditional Chinese herbs, and is found in various vegetables and fruits, including tomatoes, citrus fruits, grapefruit, onion, broccoli, cabbage and apples. Kaempferol is a flavonoid that has been shown to possess a broad range of pharmacological activities, such as antidiabetic, antioxidative, cardioprotective, angiogenic and anticancer properties $(28,29)$. A previous study revealed that kaempferol can suppress liver gluconeogenesis by reducing the activity of pyruvate carboxylase and glucose- 6 phosphatase, thereby increasing hepatic glucose metabolism and insulin resistance in diet-induced obese mice (30). In the present study, it was demonstrated that pretreatment with kaempferol at various doses had different functional effects on D-GalN/LPS-induced ALF. The results indicated that $5 \mathrm{mg} / \mathrm{kg}$ kaempferol pretreatment significantly protected against liver injury induced by D-GalN/LPS in mice, whereas a high dose of kaempferol decreased the survival rate of 
A
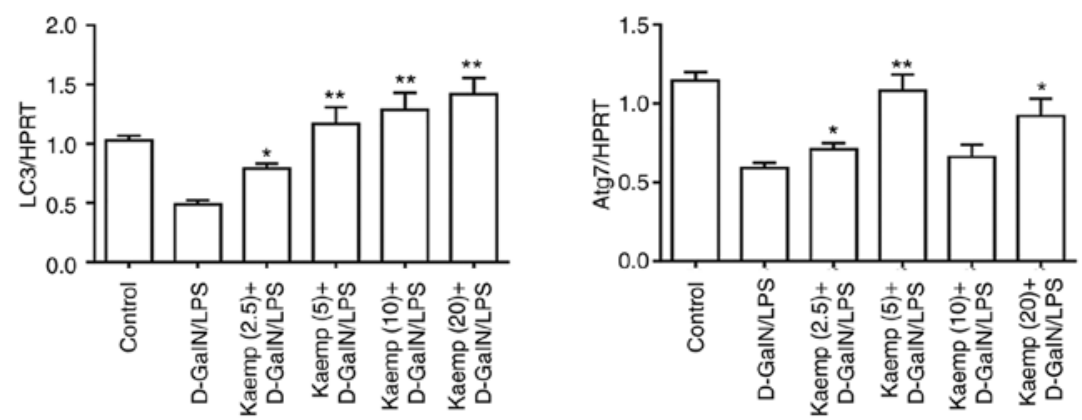

B
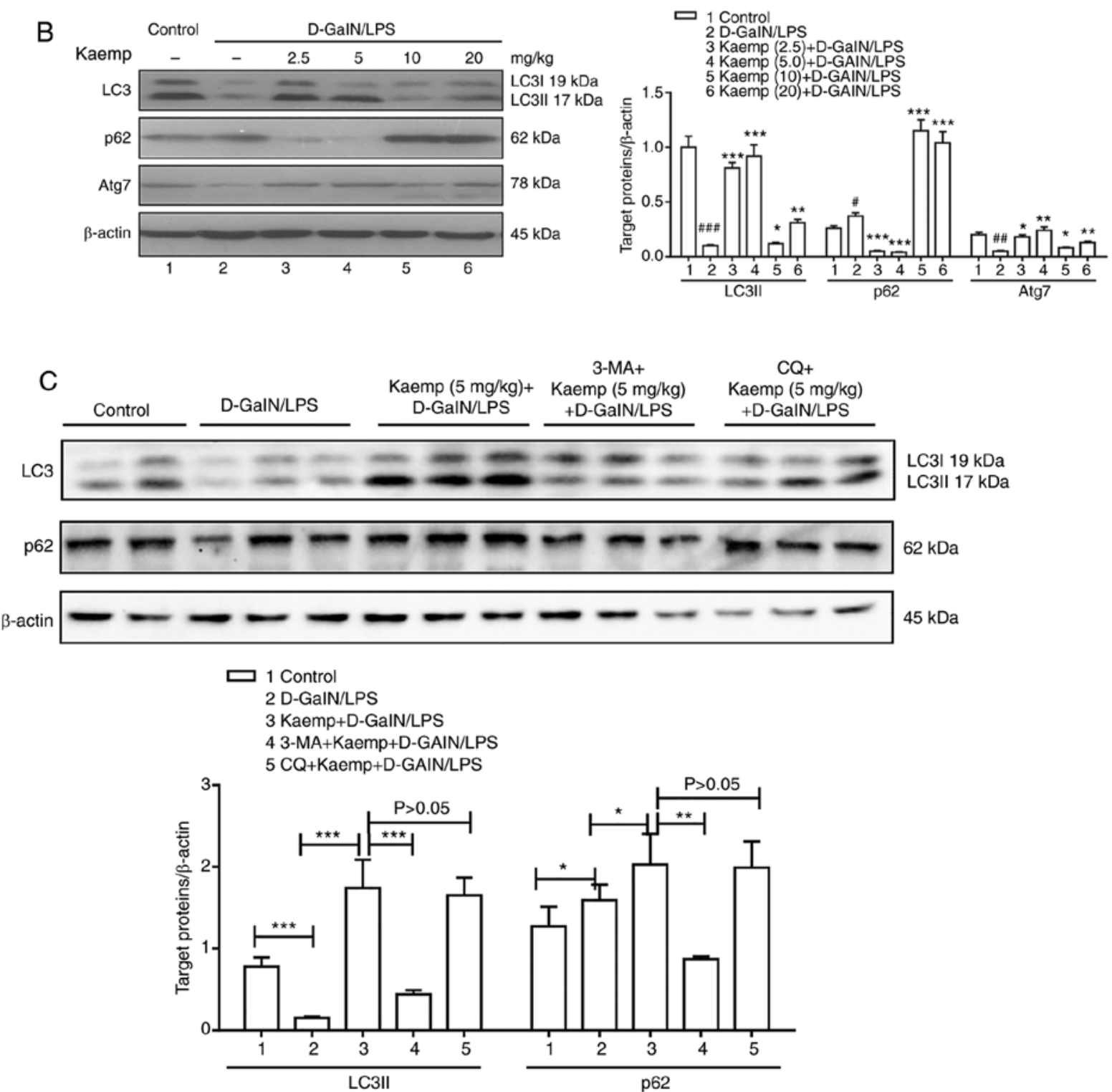

Figure 3. Effects of different doses of kaemp on liver autophagy in D-GalN/LPS-induced ALF. (A) Gene expression levels of LC3 and Atg7 in livers from mice in the different groups. HPRT was used as the reference gene. ${ }^{*} \mathrm{P}<0.05,{ }^{* *} \mathrm{P}<0.01$ vs. D-GalN/LPS group. (B) Western blotting was performed to determine hepatic protein expression levels of LC3, p62 and Atg7, with $\beta$-actin as the loading control. ${ }^{\#} \mathrm{P}<0.05,{ }^{\# \#} \mathrm{P}<0.01,{ }^{\# \# \#} \mathrm{P}<0.001$ vs. control group; ${ }^{*} \mathrm{P}<0.05,{ }^{* * *} \mathrm{P}<0.01$, ${ }^{* * * *} \mathrm{P}<0.001$ vs. D-GalN/LPS group. (C) Mice were pretreated for $2 \mathrm{~h}$ with or without kaemp (5 mg/kg, intraperitoneally), and then stimulated with D-GalN/LPS for $6 \mathrm{~h}(\mathrm{n}=12)$. Mice treated with 3-MA + kaemp + D-GalN/LPS were co-administered 3-MA $(10 \mathrm{mg} / \mathrm{kg})$ and kaemp $2 \mathrm{~h}$ before D-GalN/LPS injection $(\mathrm{n}=12)$. Mice treated with CQ + kaemp + D-GalN/LPS were co-administered CQ $(60 \mathrm{mg} / \mathrm{kg})$ and kaemp $2 \mathrm{~h}$ before D-GalN/LPS injection (n=12). A total of $2 \mathrm{~h}$ after vehicle injection, control mice were pretreated with PBS $(\mathrm{n}=12)$. Western blot analysis was performed to determine hepatic protein expression levels of LC3, p62 and $\beta$-actin. ${ }^{*} \mathrm{P}<0.05,{ }^{* * *} \mathrm{P}<0.01,{ }^{* * * *} \mathrm{P}<0.001$. Data are presented as the mean \pm SD. D-GalN/LPS, D-galactosamine/lipopolysaccharide; 3-MA, 3-Methyladenine; CQ, chloroquine; kaemp, kaempferol; Atg7, autophagy related 7; HPRT, hypoxanthine guanine phosphoribosyl transferase.

mice and resulted in more severe injury. Thus, when using kaempferol to treat ALF, it is important to pay attention to the differential effects caused by different doses, and choose the appropriate dose for treatment. 
A

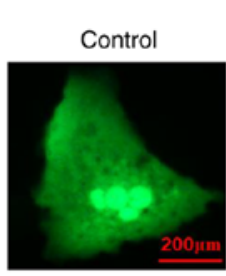
Kaemp $(0.1 \mu \mathrm{M})$
+Starvation

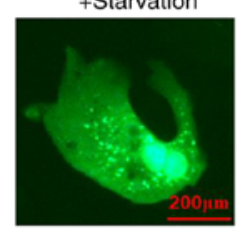

Starvation

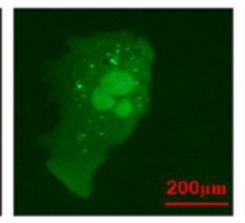

Kaemp $(1 \mu \mathrm{M})$ +Starvation

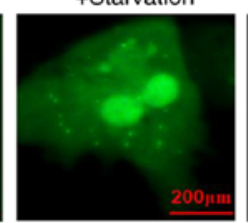

Kaemp $(0.01 \mu \mathrm{M})$ +Starvation

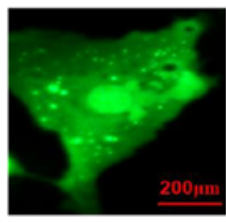

Kaemp $(10 \mu \mathrm{M})$ +Starvation

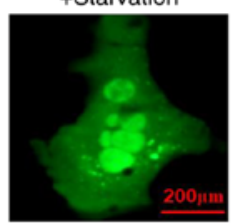

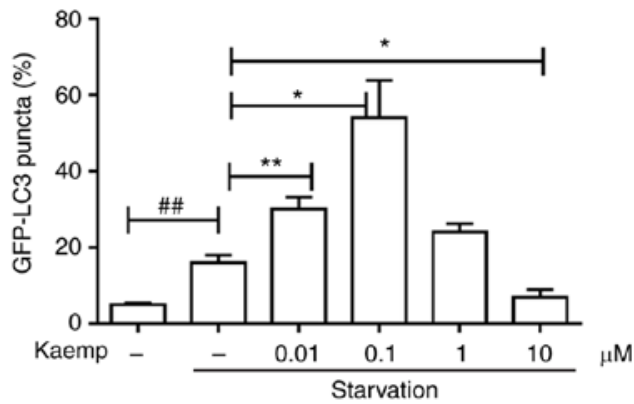

B
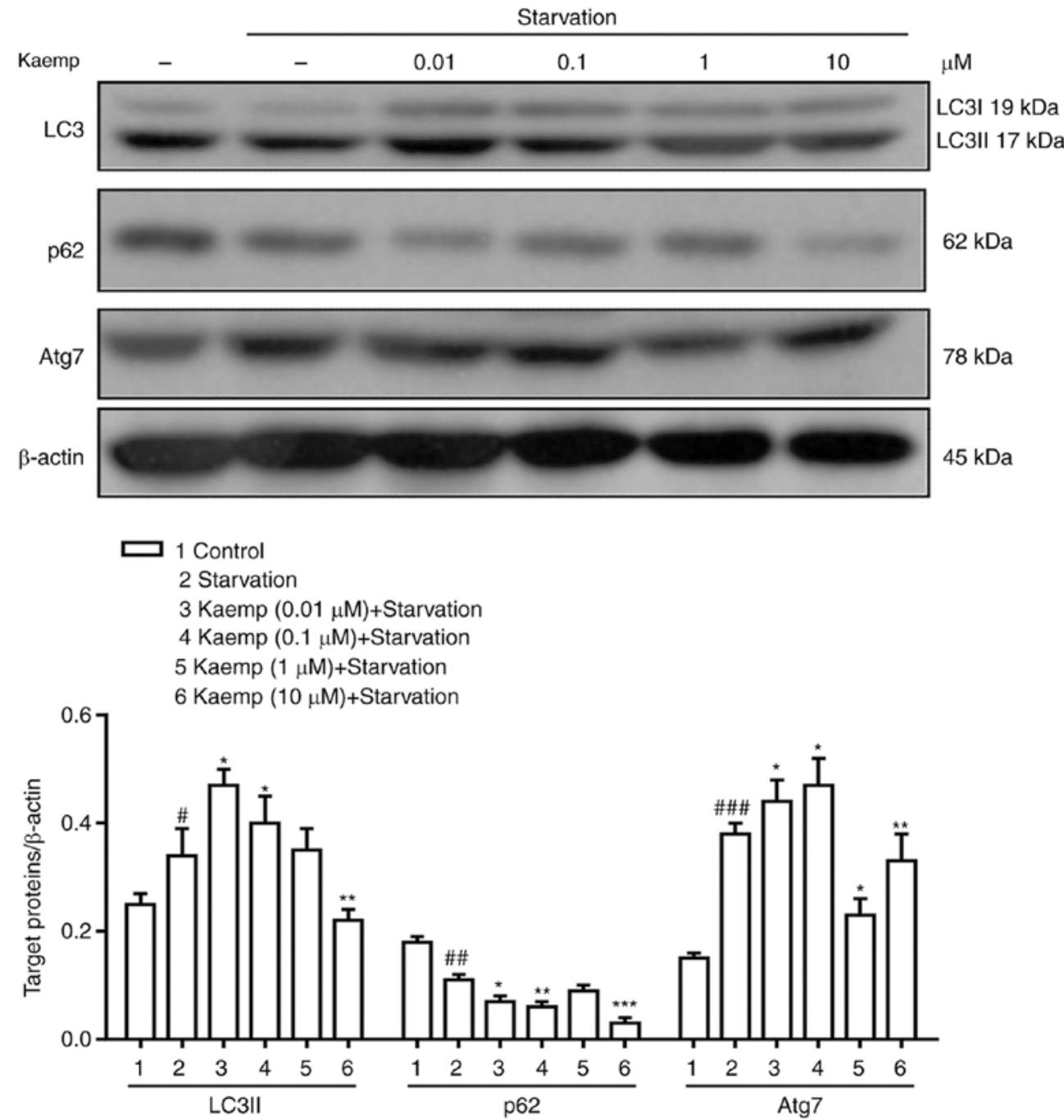

Figure 4. Effects of different doses of kaemp on starvation-induced autophagy in vitro. (A) Primary hepatocytes were transfected with GFP-LC3 plasmids for $12 \mathrm{~h}$ and preincubated with kaemp $(0.01,0.1,1$ or $10 \mu \mathrm{M})$ for $12 \mathrm{~h}$, after which, the formation of autophagosomes was observed. (B) Western blotting was performed to determine the protein expression levels of autophagy-related proteins, including LC3, p62 and Atg7, in primary hepatocytes under conditions of starvation. Data are presented as the mean $\pm \mathrm{SD} .{ }^{\#} \mathrm{P}<0.05,{ }^{\# \#} \mathrm{P}<0.01,{ }^{\# \# \#} \mathrm{P}<0.001$ vs. control group; ${ }^{*} \mathrm{P}<0.05,{ }^{* *} \mathrm{P}<0.01,{ }^{* * *} \mathrm{P}<0.001$ vs. starvation group. kaemp, kaempferol; Atg7, autophagy related 7.

ALF is associated with high mortality rates; the clinical symptoms include coagulopathy, hepatic dysfunction and abnormal liver biochemical parameters. In addition, ALF is closely associated with the inflammatory response, and is an injury process associated with inflammation-mediated hepatocellular carcinoma (31). There are currently no effective treatments for ALF. Our previous study showed that endoplasmic reticulum stress can reduce inflammation by regulating the 
A
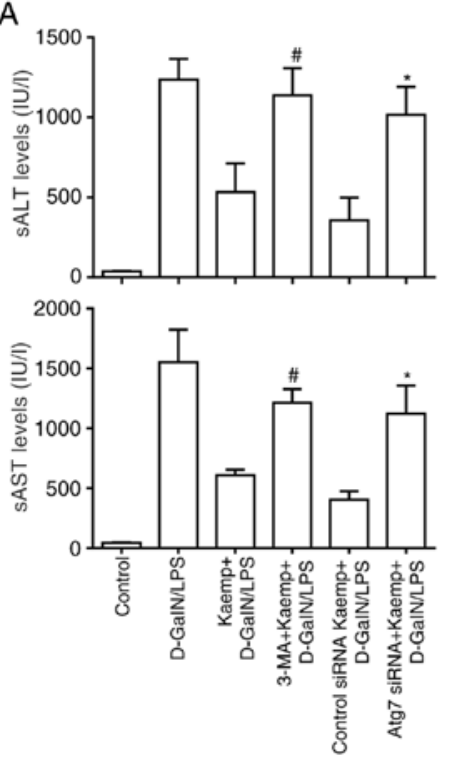

B

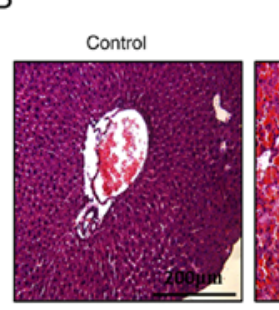

3-MA+Kaemp+

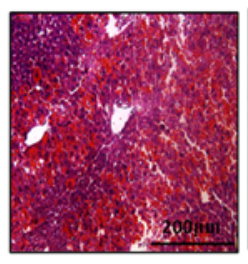

Control siRNA Kaemp+

D-GaIN/LPS

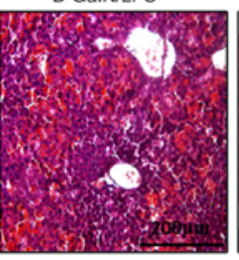

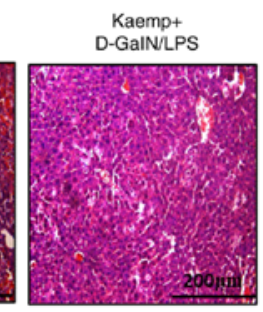

Atg7 siRNA+Kaemp+

D-GalN/LPS

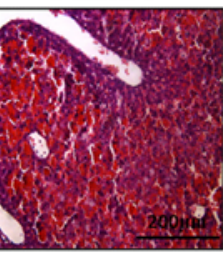

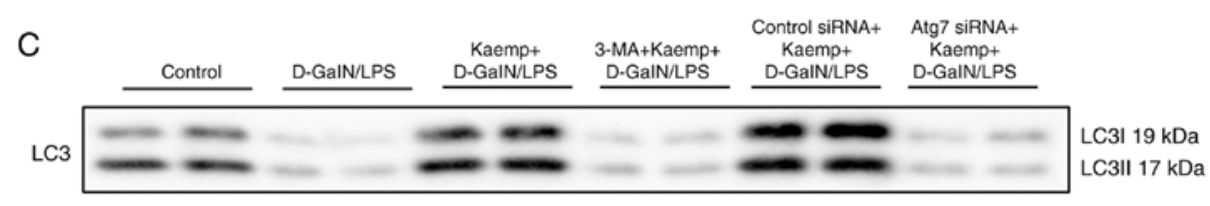
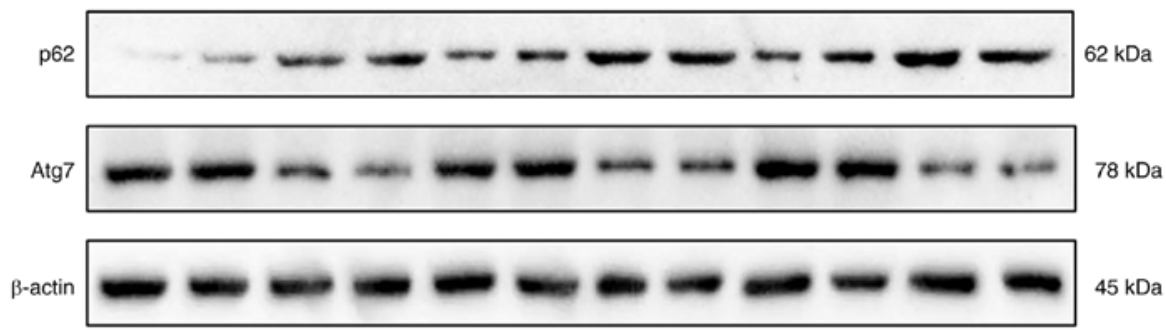

1 Control

2 D-GalN/LPS

3 Kaemp+D-GaIN/LPS

4 3-MA+Kaemp+D-GalN/LPS

5 Control siRNA+Kaemp+D-GaIN/LPS

6 Atg7 siRNA+Kaemp+D-GaIN/LPS

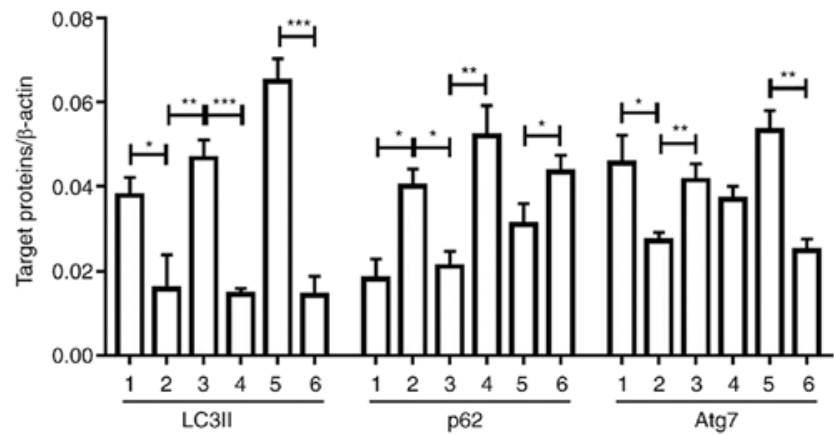

Figure 5. Kaemp protects mice against ALF by regulating the autophagy pathway in the liver. Mice were pretreated for $2 \mathrm{~h}$ with or without kaemp $(5 \mathrm{mg} / \mathrm{kg}$, intraperitoneally), and then stimulated with D-GalN/LPS for $6 \mathrm{~h}(\mathrm{n}=20)$. Mice treated with 3-MA + kaemp + D-GalN/LPS were administered 3-MA (10 mg/kg) and kaemp $2 \mathrm{~h}$ before D-GalN/LPS injection $(\mathrm{n}=20)$. Mice treated with control siRNA or Atg7 siRNA + kaemp + D-GalN/LPS were injected via tail vein for $48 \mathrm{~h}$ with control or Atg7 siRNA ( $3 \mathrm{mg} / \mathrm{kg}$ ), and were administered kaemp $2 \mathrm{~h}$ before D-GalN/LPS injection ( $\mathrm{n}=20$ ). A total of $2 \mathrm{~h}$ after vehicle injection, control mice were pretreated with PBS $(\mathrm{n}=20)$. (A) sAST and sALT enzyme levels in the different groups. " $\mathrm{P}<0.05 \mathrm{vs.} \mathrm{kaemp} \mathrm{+} \mathrm{D-GalN/LPS} \mathrm{group;}$ ${ }^{*} \mathrm{P}<0.05$ vs. kaemp + D-GalN/LPS + control siRNA group. (B) Representative H\&E-stained liver sections from different groups. (C) Western blot analysis was performed to determine hepatic protein expression levels of LC3, p62, Atg7 and $\beta$-actin in the different groups. ${ }^{*} \mathrm{P}<0.05,{ }^{{ }^{* *}} \mathrm{P}<0.01,{ }^{* * * *} \mathrm{P}<0.001$. Data are presented as the mean $\pm \mathrm{SD}$. ALF, acute liver failure; sALT, serum alanine aminotransferase; sAST, serum aspartate aminotransferase; D-GalN/LPS, D-galactosamine/lipopolysaccharide; Atg7, autophagy related 7; 3-MA, 3-Methyladenine; kaemp, kaempferol; siRNA, small interfering RNA.

immune mechanism in ALF (32). The present study suggested that 10 and $20 \mathrm{mg} / \mathrm{kg}$ kaempferol pretreatment increased the expression of proinflammatory cytokines, and the expression levels of proinflammatory cytokines were significantly decreased 
in the ALF mice pretreated with 2.5 or $5 \mathrm{mg} / \mathrm{kg}$ kaempferol. Therefore, these data suggest that a high-dose of kaempferol pretreatment can promote the hepatic inflammatory response, whereas low-dose kaempferol pretreatment can significantly suppress it in D-GalN/LPS-induced ALF. The levels of proinflammatory cytokines were downregulated by the low dose of kaempferol, which may be the result of the increased production of anti-inflammatory cytokines, such as IL-13, which reduce TNF- $\alpha$ production in vivo (33). A previous study revealed that IL-13 significantly reduced the lethal effects of LPS in a neonatal mouse model of endotoxin shock (34). In a similar manner to IL-10, a high dose of kaempferol may also decrease the production of IL-13 (35).

Autophagy is a process of self-digestion that attempts to maintain cell homeostasis, supply a variety of substrates for cellular energy generation and ensures cell survival under stressful conditions to a certain degree. Autophagy is an important physiological process, and is tightly associated with regulation of cell death in specific tissues, such as the liver and brain (36). Autophagy and inflammation are also closely related (37). Our previous study reported that peroxisome proliferator activated receptor (PPAR) $\alpha$ activation alleviated the inflammatory response by promoting autophagy in ALF model mice induced by D-GalN/LPS (38). Moreover, it was confirmed that inhibition of GSK-3 $\beta$ activity increased PPAR $\alpha$ expression and decreased the inflammatory response by further increasing autophagy (32). The present study demonstrated that different doses of kaempferol had differential effects on the induction of autophagy and autophagosome formation in vivo and in vitro. The presence of autophagic flux was identified based on the increased LC3 expression combined with decreased p62 expression (39). These current results indicated that a low-dose of kaempferol upregulated the expression levels of genes associated with autophagy, and increased LC3II conversion and p62 degradation, whereas a high-dose of kaempferol decreased LC3II conversion and p62 degradation, and increased autophagosome formation. Moreover, pretreatment with CQ did not significantly alter the effects of $5 \mathrm{mg} / \mathrm{kg}$ kaempferol on the expression levels of LC3 and p62 in the ALF mouse model. It was thus concluded that the inflammatory response was attenuated by pretreatment with a low dose of kaempferol, and that this low dose upregulated autophagic activity. However, it is possible that the effects of kaempferol on the autophagic flux at different concentrations is a highly complicated physiological phenomenon, and therefore requires further study in the context of ALF.

Previous studies have shown that the excessive activation of mTOR can result in disordered apoptosis and autophagy, which leads to the occurrence of human immunodeficiency virus (HIV)-related diseases (40). Hence, it could be hypothesized that kaempferol may also be useful for conditions characterized by dysregulated autophagy, such as HIV-associated neurodegenerative diseases. Additionally, it also can be assumed that kaempferol may be effective against diseases characterized by abnormal activation of the PIK3/Akt/mTOR pathway that benefit from mTOR inhibitors, including infectious diseases, such as HIV and severe acute respiratory syndrome coronavirus 2 (41-43), and autoimmune diseases, such as multiple sclerosis and systemic lupus erythematosus (44-46), as well as cancer (47-49).

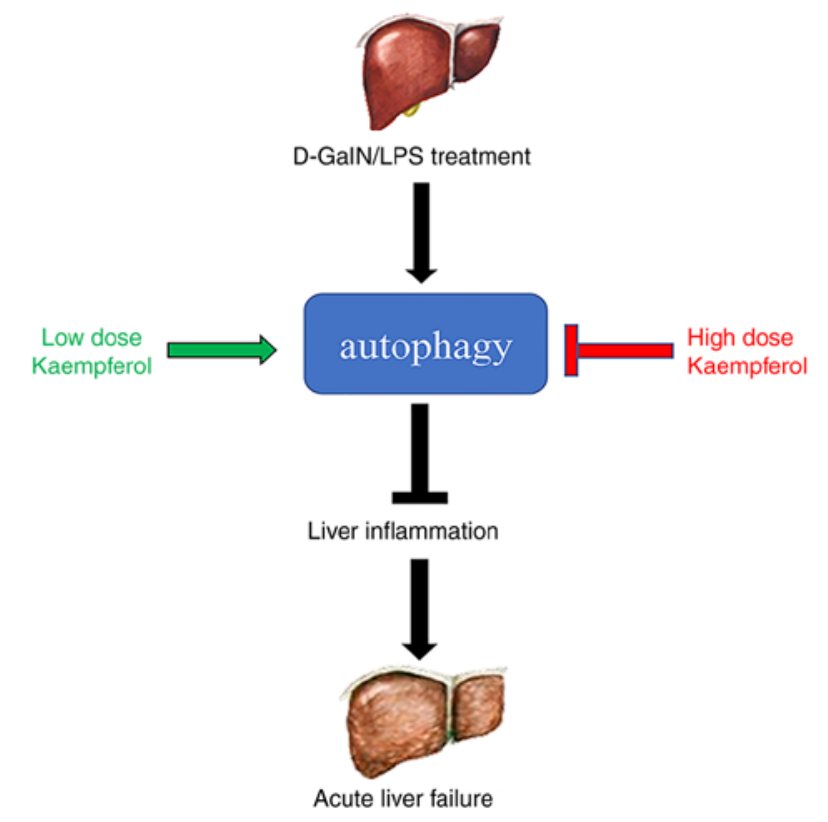

Figure 6. Schematic representation of the study findings. The effects of kaempferol on ALF at various doses had different functional outcomes, which was mediated by differential regulation of the autophagy pathway. ALF, acute liver failure; D-GalN/LPS, D-galactosamine/lipopolysaccharide.

In reviewing the literature, kaempferol has been shown to antagonize Toll-like receptor (TLR) signaling, and in particular TLR4 signaling (50). It has previously been observed that autophagy can be regulated by the TLR4 signaling pathway $(51,52)$. TLR4 inhibitors, including VGX-1027 and monoclonal antibodies, have been reported to possess multiple functions in models of immune-inflammation and autoimmunity, such as anti-inflammatory and anti-injury effects, and they are being developed for use in clinical settings (53-56). Therefore, kaempferol may be used as an emerging class of TLR4 inhibitor to treat immune inflammation and autoimmune diseases, which highlights the significant pharmacological potential of kaempferol.

Although this study revealed the different effects of different doses of kaempferol on D-GalN/LPS-induced ALF via regulation of the autophagy pathway, the specific molecular pathway through which autophagy is regulated remains unclear. Further research is required to explore how autophagy is regulated.

In conclusion, the results of the present study suggested that the effects of kaempferol on ALF at various doses had different functional outcomes, and this was mediated by differential regulation of the autophagy pathway. It was found that a low dose of kaempferol can significantly protect mice from liver injury in ALF. A schematic diagram of the potential mechanisms identified by the present study is presented in Fig. 6. Overall, the optimal dose of kaempferol should be further assessed, and this may serve as an effective strategy for treatment of ALF. For further preclinical studies of autophagy agonists, it is necessary to develop clinically applicable therapeutic strategies for ALF.

\section{Acknowledgements}

Not applicable. 


\section{Funding}

This study was supported by the National Natural Science Foundation of China (grant nos. 81770611 and 82002243); the Demonstrating Application and Research of Clinical Diagnosis and Treatment Technology in Beijing (grant nos. Z191100006619096 and Z191100006619097); Key Projects of the Beijing Municipal Education Commission's Science and Technology Plan (grant no. KZ202010025035); Beijing Municipal Administration of Hospitals Clinical Medicine Development of Special Funding Support (grant no. XMLX201830); Key Medical Major of Beijing Sailing Plan (grant no. ZYLX201819); the National Science and Technology Key Project on 'Major Infectious Diseases such as HIV/AIDS, Viral Hepatitis Prevention and Treatment' (grant nos. 2018ZX10301407-005-002 and 2018ZX103 02205-004-004); the Beijing Talents foundation (grant no. 2018000021469G289); Beijing Hospitals Authority Youth Programme (grant no. QML20201702); the Scientific Research Project of Beijing Youan Hospital, Capital Medical University (grant no. YNKTQN20180202); and the Key Public Relations Project of Capital Health Development Scientific Research Project (grant nos. SF2020-1-1151 and SF2021-1G-2181).

\section{Availability of data and materials}

The datasets used and/or analyzed during the current study are available from the corresponding author on reasonable request.

\section{Authors' contributions}

YT and FR wrote the manuscript and performed the experiments. YT and LX collected and analyzed the data. FR and XZ designed the experiments. FR and XZ confirm the authenticity of all the raw data. All authors read and approved the final manuscript.

\section{Ethics approval and consent to participate}

All animal experiments were reviewed and approved by Institutional Animal Care and Use Committee of Capital Medical University (approval no. AEEI-2020-009 on 2019/12/30).

\section{Patient consent for publication}

Not applicable.

\section{Competing interests}

The authors declare that they have no competing interests.

\section{References}

1. European Association for the Study of the Liver. Electronic address: easloffice@easloffice.eu; European Association for the Study of the Liver: EASL clinical practical guidelines on the management of acute (fulminant) liver failure. J Hepatol 66 1047-1081, 2017
2. Rajendran P, Rengarajan T, Nandakumar N, Palaniswami R, Nishigaki $Y$ and Nishigaki I: Kaempferol, a potential cytostatic and cure for inflammatory disorders. Eur J Med Chem 86: 103-112, 2014.

3. Sharifi-Rad M,Fokou PVT,SharopovF,MartorellM,Ademiluyi AO, Rajkovic J, Salehi B, Martins N, Iriti M and Sharifi-Rad J: Antiulcer agents: From plant extracts to phytochemicals in healing promotion. Molecules 23: 1751, 2018.

4. Imran M, Salehi B, Sharifi-Rad J, Aslam Gondal T, Saeed F, Imran A, Shahbaz M, Tsouh Fokou PV, Umair Arshad M, Khan H, et al: Kaempferol: A key emphasis to its anticancer potential. Molecules 24: 2277, 2019.

5. Mahobiya A,Singh TU,Rungsung S,KumarT,Chandrasekaran G, Parida S and Kumar D: Kaempferol-induces vasorelaxation via endothelium-independent pathways in rat isolated pulmonary artery. Pharmacol Rep 70: 863-874, 2018.

6. Torres-Villarreal D, Camacho A, Castro H, Ortiz-Lopez R and de la Garza AL: Anti-obesity effects of kaempferol by inhibiting adipogenesis and increasing lipolysis in 3T3-L1 cells. J Physiol Biochem 75: 83-88, 2019.

7. Kashafi E, Moradzadeh M, Mohamadkhani A and Erfanian S: Kaempferol increases apoptosis in human cervical cancer HeLa cells via PI3K/AKT and telomerase pathways. Biomed Pharmacother 89: 573-577, 2017.

8. Wu P, Meng X, Zheng H, Zeng Q, Chen T, Wang W, Zhang X and Su J: Kaempferol attenuates ROS-Induced hemolysis and the molecular mechanism of its induction of apoptosis on bladder cancer. Molecules 23: 2592, 2018.

9. Murakami T, Kohno K, Ninomiya K, Matsuda $\mathrm{H}$ and Yoshikawa M: Medicinal foodstuffs. XXV. Hepatoprotective principle and structures of ionone glucoside, phenethyl glycoside, and flavonol oligoglycosides from young seedpods of garden peas, Pisum sativum L. Chem Pharm Bull (Tokyo) 49: 1003-1008, 2001.

10. Xiong Q, Fan W, Tezuka Y, Adnyana IK, Stampoulis P, Hattori M, Namba T and Kadota S: Hepatoprotective effect of Apocynum venetum and its active constituents. Planta Med 66: 127-133, 2000.

11. Matsuda H, Ninomiya $K$, Shimoda $H$ and Yoshikawa $M$ : Hepatoprotective principles from the flowers of Tilia argentea (linden): Structure requirements of tiliroside and mechanisms of action. Bioorg Med Chem 10: 707-712, 2002.

12. García-Mediavilla V, Crespo I, Collado PS, Esteller A, Sánchez-Campos S, Tuñón MJ and González-Gallego J: The anti-inflammatory flavones quercetin and kaempferol cause inhibition of inducible nitric oxide synthase, cyclooxygenase- 2 and reactive $\mathrm{C}$-protein, and down-regulation of the nuclear factor kappaB pathway in chang liver cells. Eur J Pharmacol 557: 221-229, 2007.

13. Tsai MS, Wang YH, Lai YY, Tsou HK, Liou GG, Ko JL and Wang SH: Kaempferol protects against propacetamol-induced acute liver injury through CYP2E1 inactivation, UGT1A1 activation, and attenuation of oxidative stress, inflammation and apoptosis in mice. Toxicol Lett 290: 97-109, 2018.

14. Wang H, Chen L, Zhang X, Xu L, Xie B, Shi H, Duan Z, Zhang H and Ren F: Kaempferol protects mice from d-GalN/LPS-induced acute liver failure by regulating the ER stress-Grp78-CHOP signaling pathway. Biomed Pharmacother 111: 468-475, 2019.

15. McEwan DG: Host-pathogen interactions and subversion of autophagy. Essays Biochem 61: 687-697, 2017.

16. Jiao L, Zhang HL, Li DD, Yang KL, Tang J, Li X, Ji J, Yu Y, Wu R, Ravichandran S, et al: Regulation of glycolytic metabolism by autophagy in liver cancer involves selective autophagic degradation of HK2 (hexokinase 2). Autophagy 14: 671-684, 2018.

17. Madrigal-Matute J and Cuervo AM: Regulation of liver metabolism by autophagy. Gastroenterology 150: 328-339, 2016.

18. Ren F, Zhang L, Zhang X, Shi H, Wen T, Bai L, Zheng S, Chen Y, Chen D, Li L and Duan Z: Inhibition of glycogen synthase kinase $3 \beta$ promotes autophagy to protect mice from acute liver failure mediated by peroxisome proliferator-activated receptor $\alpha$. Cell Death Dis 7: e2151, 2016.

19. Mignon A, Rouquet N, Fabre M, Martin S, Pagès JC, Dhainaut JF, Kahn A, Briand P and Joulin V: LPS Challenge in D-galactosamine-Sensitized mice accounts for caspase-dependent fulminant hepatitis, not for septic shock. Am J Resp Crit Care Med 159 (4 Pt 1): 1308-1315, 1999.

20. Nakama T, Hirono S, Moriuchi A, Hasuike S, Nagata K, Hori T, Ido A, Hayashi $\mathrm{K}$ and Tsubouchi $\mathrm{H}$ : Etoposide prevents apoptosis in mouse liver with D-galactosamine/lipopolysaccharide-induced fulminant hepatic failure resulting in reduction of lethality. Hepatology 33: 1441-1450, 2001. 
21. Miller S, Oleksy A, Perisic O and Williams RL: Finding a fitting shoe for Cinderella: Searching for an autophagy inhibitor. Autophagy 6: 805-807, 2010.

22. Ahlberg J, Berkenstam A, Henell $\mathrm{F}$ and Glaumann $\mathrm{H}$ : Degradation of short and long lived proteins in isolated rat liver lysosomes. Effects of $\mathrm{pH}$, temperature, and proteolytic inhibitors. J Biol Chem 260: 5847-5854, 1985.

23. Karmen A, Wroblewski F and Ladue JS: Transaminase activity in human blood. J Clin Invest 34: 126-131, 1955.

24. Livak KJ and Schmittgen TD: Analysis of relative gene expression data using real-time quantitative PCR and the 2(-Delta Delta $\mathrm{C}(\mathrm{T})$ ) method. Methods 25: 402-408, 2001.

25. Klaunig JE, Goldblatt PJ, Hinton DE, Lipsky MM, Chacko J and Trump BF: Mouse liver cell culture. I. Hepatocyte isolation. In vitro 17: 913-925, 1981.

26. Nguyen TB, Louie SM, Daniele JR, Tran Q, Dillin A, Zoncu R, Nomura DK and Olzmann JA: DGAT1-Dependent lipid droplet biogenesis protects mitochondrial function during starvation-induced autophagy. Dev Cell 42: 9-21.e5, 2017.

27. Zhang X, Ding J, Gou C, Wen T, Li L, Wang X, Yang H, Liu D, Lou J, Chen D, et al: Qingchangligan formula attenuates the inflammatory response to protect the liver from acute failure induced by d-galactosamine/lipopolysaccharide in mice. J Ethnopharmacol 201: 108-116, 2017.

28. Devi KS, Mishra D, Roy B, Ghosh SK and Maiti TK: Assessing the immunomodulatory role of heteroglycan in a tumor spheroid and macrophage co-culture model system. Carbohyd Polym 127: $1-10,2015$

29. Zang Y, Zhang L, Igarashi K and Yu C: The anti-obesity and anti-diabetic effects of kaempferol glycosides from unripe soybean leaves in high-fat-diet mice. Food Funct 6: 834-841, 2015.

30. Alkhalidy H, Moore W, Wang A, Luo J, McMillan RP, Wang Y, Zhen W, Hulver MW and Liu D: Kaempferol ameliorates hyperglycemia through suppressing hepatic gluconeogenesis and enhancing hepatic insulin sensitivity in diet-induced obese mice. J Nutr Biochem 58: 90-101, 2018.

31. Bernal W and Wendon J: Acute liver failure. N Engl J Med 369: 2525-2534, 2013

32. Ren F, Zhou L, Zhang X, Wen T, Shi H, Xie B, Li Z, Chen D, Wang $\mathrm{Z}$ and Duan Z: Endoplasmic reticulum stress-activated glycogen synthase kinase $3 \beta$ aggravates liver inflammation and hepatotoxicity in mice with acute liver failure. Inflammation 38 1151-1165, 2015.

33. Zaccone P, Phillips J, Conget I, Gomis R, Haskins K, Minty A, Bendtzen K, Cooke A and Nicoletti F: Interleukin-13 prevents autoimmune diabetes in NOD mice. Diabetes 48: 1522-1528, 1999.

34. Nicoletti F, Mancuso G, Cusumano V, Di Marco R, Zaccone P, Bendtzen K and Teti G: Prevention of endotoxin-induced lethality in neonatal mice by interleukin-13. Eur J Immunol 27: 1580-1583, 1997.

35. Chung MJ, Pandey RP, Choi JW, Sohng JK, Choi DJ and Park YI: Inhibitory effects of kaempferol-3-O-rhamnoside on ovalbumin-induced lung inflammation in a mouse model of allergic asthma. Int Immunopharmacol 25: 302-310, 2015.

36. Russo M and Russo GL: Autophagy inducers in cancer. Biochem Pharmacol 153: 51-61, 2018.

37. Fésüs L, Demény MÁ and Petrovski G: Autophagy shapes inflammation. Antioxid Redox Sign 14: 2233-2243, 2010

38. Jiao M, Ren F, Zhou L, Zhang X, Zhang L, Wen T, Wei L, Wang X, Shi H, Bai L, et al: Peroxisome proliferator-activated receptor $\alpha$ activation attenuates the inflammatory response to protect the liver from acute failure by promoting the autophagy pathway. Cell Death Dis 5: e1397, 2014

39. Klionsky DJ, Abdelmohsen K, Abe A, Abedin MJ, Abeliovich H, Acevedo Arozena A, Adachi H, Adams CM, Adams PD, Adeli K, et al: Guidelines for the use and interpretation of assays for monitoring autophagy (3rd edition). Autophagy 12: 1-222, 2016.

40. Nicoletti F, Fagone P, Meroni P, McCubrey J and Bendtzen K: mTOR as a multifunctional therapeutic target in HIV infection. Drug Discov Today 16: 715-721, 2011.

41. Donia M, McCubrey JA, Bendtzen K and Nicoletti F: Potential use of rapamycin in HIV infection. Br J Clin Pharmacol 70 784-793, 2010
42. Nicoletti F, Lapenta C, Donati S, Spada M, Ranazzi A, Cacopardo B, Mangano K, Belardelli F, Perno C and Aquaro S: Inhibition of human immunodeficiency virus (HIV-1) infection in human peripheral blood leucocytes-SCID reconstituted mice by rapamycin. Clin Exp Immunol 155: 28-34, 2009.

43. Fagone P, Ciurleo R, Lombardo SD, Iacobello C, Palermo CI, Shoenfeld Y, Bendtzen K, Bramanti P and Nicoletti F: Transcriptional landscape of SARS-CoV-2 infection dismantles pathogenic pathways activated by the virus, proposes unique sex-specific differences and predicts tailored therapeutic strategies. Autoimmun Rev 19: 102571, 2020.

44. Mammana S, Bramanti P, Mazzon E, Cavalli E, Basile MS, Fagone P,Petralia MC, McCubrey JA, Nicoletti F and Mangano K: Preclinical evaluation of the PI3K/Akt/mTOR pathway in animal models of multiple sclerosis. Oncotarget 9: 8263-8277, 2018.

45. Donia M, Mangano K, Amoroso A, Mazzarino MC, Imbesi R, Castrogiovanni P, Coco M, Meroni P and Nicoletti F: Treatment with rapamycin ameliorates clinical and histological signs of protracted relapsing experimental allergic encephalomyelitis in Dark Agouti rats and induces expansion of peripheral CD4+CD25+Foxp3+regulatory T cells.J Autoimmun 33: 135-140, 2009.

46. Ji L, Xie W and Zhang Z: Efficacy and safety of sirolimus in patients with systemic lupus erythematosus: A systematic review and meta-analysis. Semin Arthritis Rheum 50: 1073-1080, 2020.

47. Xiao W, Liu Y, Dai M, Li Y, Peng R, Yu S and Liu H: Rotenone restrains colon cancer cell viability, motility and epithelial-mesenchymal transition and tumorigenesis in nude mice via the PI3K/AKT pathway. Int J Mol Med 46: 700-708, 2020.

48. Zhang Z, Li N, Liu S, Jiang M, Wan J, Zhang Y, Wan L, $\mathrm{Xie} C$ and Le A: Overexpression of IFIT2 inhibits the proliferation of chronic myeloid leukemia cells by regulating the BCR-ABL/AKT/mTOR pathway. Int J Mol Med 45: 1187-1194. 2020.

49. Liu Z, Liu H, Li Y, Wang Y, Xing R, Mi F, Xiang C and Fu R: Adiponectin inhibits the differentiation and maturation of osteoclasts via the mTOR pathway in multiple myeloma. Int J Mol Med 45: 1112-1120, 2020.

50. Cheng X, Yang YL, Yang H, Wang YH and Du GH: Kaempferol alleviates LPS-induced neuroinflammation and BBB dysfunction in mice via inhibiting HMGB1 release and down-regulating TLR4/MyD88 pathway. Int Immunopharmacol 56: 29-35, 2018.

51. Xu Y, Jagannath C, Liu XD, Sharafkhaneh A, Kolodziejska KE and Eissa NT: Toll-like receptor 4 is a sensor for autophagy associated with innate immunity. Immunity 27: 135-144, 2007.

52. Delgado MA, Elmaoued RA, Davis AS, Kyei G and Deretic V: Toll-like receptors control autophagy. Embo J 27: 1110-1121, 2008.

53. Stojanovic I, Cuzzocrea S, Mangano K, Mazzon E, Miljkovic D, Wang M, Donia M, Al Abed Y, Kim J, Nicoletti F, et al: In vitro, ex vivo and in vivo immunopharmacological activities of the isoxazoline compound VGX-1027: Modulation of cytokine synthesis and prevention of both organ-specific and systemic autoimmune diseases in murine models. Clin Immunol 123: 311-323, 2007.

54. Fagone P, Muthumani K, Mangano K, Magro G, Meroni PL, Kim JJ, Sardesai NY, Weiner DB and Nicoletti F: VGX-1027 modulates genes involved in lipopolysaccharide-induced Toll-like receptor 4 activation and in a murine model of systemic lupus erythematosus. Immunology 142: 594-602, 2014.

55. Lee JC, Menacherry S, Diehl MC, Giffear MD, White CJ, Juba R, Bagarazzi ML, Muthumani K, Boyer J, Agarwal V, et al: Safety, bioavailability, and pharmacokinetics of VGX-1027-A novel oral anti-inflammatory drug in healthy human subjects. Clin Pharmacol Drug Dev 5: 91-101, 2016.

56. Huang C, Pan L, Lin F, Dai H and Fu R: Monoclonal antibody against Toll-like receptor 4 attenuates ventilator-induced lung injury in rats by inhibiting MyD88- and NF- $\kappa \mathrm{B}$-dependent signaling. Int J Mol Med 39: 693-700, 2017.

This work is licensed under a Creative Commons Attribution-NonCommercial-NoDerivatives 4.0 International (CC BY-NC-ND 4.0) License. 